\title{
Enhancement of the Inotropic Action of Glucagon by Small Concentration of Angiotensin
}

\author{
Kiyoshi Inoue, M.D., Harold Smulyan, M.D., \\ Edgardo Mucha, M.D., and Robert H. Eich, M.D.
}

\section{SummaRy}

Under pentobarbital sodium anesthesia and bilateral vagotomy, studies were carried out in 2 groups of 3 dogs and another group of 4 and 7. Group 1 (4 dogs): Continuous i.v. infusion of angiotensin $(5 \mathrm{ng} / \mathrm{Kg} /$ $10 \mathrm{ml} / \mathrm{min}$ ) produced no effects on $\mathrm{LV}$ contractility $(\mathrm{LV} \mathrm{dp} / \mathrm{dt}$, maximum aortic flow velocity), LV stroke volume, heart rate or mean systemic BP. Group 2 (7 dogs): This concentration of angiotensin produced a greater increase in LVdp/dt following i.v. glucagon than those produced by glucagon alone. This potentiation with angiotensin, however, did not occur using epinephrine or isoproterenol, doses of which were chosen to provide a similar increase in LVdp/dt. Augmentation by angiotensin of chronotropic effects of these 3 drugs was not observed. Group 3 (3 dogs): Modification by angiotensin of inotropic effect of glucagon could be reproducible in propranolol pretreated dogs, and in 6 papillary muscle preparations (Group 4-3 dogs). The results suggest that small concentration of angiotensin (probably physiological level) may act on the cardiac contraction by indirect fashion.

\section{Additional lndexing Words :}

Beta adrenergic blockade Catecholamine Calcium ion Cyclic 3', 5' AMP Essential hypertension Cardiac output

\footnotetext{
A NGIOTENSIN has been known as a potent vasopressor agent which acts directly on the arteriolar smooth muscles. Other actions of this agent have been demonstrated: Angiotensin, for example, acts to release adrenal catecholamines ${ }^{1}$ and stimulates both the central ${ }^{2)-4)}$ and peripheral(5)-8) nervous systems. Recently, angiotensin has also been shown to produce a significant positive inotropic effect on mammalian ventricular myocardium. ${ }^{9}{ }^{1-13}$ ) The

From the Department of Medicine, State University of New York, Upstate Medical Center, Syracuse, New York.

This study was supported by research grants from the U.S. Public Health Service, National Institute of Health (HE 05410), and the Heart Association of Upstate New York, Inc. (PN-10046).

Mailing Address: Dr. Kiyoshi Inoue, M.D., Second Department of Internal Medicine, Tokyo University Hospital, Tokyo, Japan.

This work was in part presented at the 43rd Scientific Session of the American Heart Association in November 1970 at Atlantic City, N.J.

Reccived for publication February 7, 1973.
} 
vasopressor and the positive inotropic actions are of importance in the pathogenesis of high cardiac output hypertension as demonstrated in the chronic stage of Goldblatt animals ${ }^{14), 15)}$ or in some groups of patients with renovascular, ${ }^{16)}$ or essential hypertension. ${ }^{17)}$

However, no increase in blood angiotensin activity could be demonstrated, and this led us to speculate that a low level of angiotensin (probably variations within physiological levels) may play a role in this type of hypertension. Actually, angiotensin doses, either insufficient to produce a pressor effect or much less concentrated (approaching circulating physiological levels) have been demonstrated to produce a stimulant effect on peripheral alpha adrenergic vasoconstrictor mechanisms, ${ }^{61,8), 18)-20)}$ and to facilitate the sympathomimetics at various organ levels. ${ }^{21-24}$ ) There have been no systematic studies of the effect of low concentration of angiotensin on the heart. For this reason, this study was designed to determine the cardiac action of low concentration of this agent.

\section{Method}

A total of 17 adult mongrel dogs weighing between 13 and $26 \mathrm{Kg}$ were studied. Experiments were performed in 4 groups. There are 2 groups of 3 dogs and another group of 7 and 4.

Dog with open heart preparation-Group 1 (4 dogs): Hemodynamic effects of small doses of angiotensin were studied. Dogs were anesthetized with intravenous pentobarbital sodium $(30 \mathrm{mg} / \mathrm{Kg})$. The cervical vagi were severed bilaterally. Positive pressure respiration was maintained by a Harvard respirator pump. Systemic arterial pressure was measured from the femoral artery using a Statham model $\mathrm{P} 23-\mathrm{Db}$ strain gauge. The chest was opened through a midline incision, the pericardium opened and the heart suspended in a pericardial cradle. The left ventricular (LV) intracavitary pressure was obtained by a large bore cannulae inserted into the ventricle through the apical dimple. The output on LV pressure was connected to an R.C. circuit in order to measure the maximum rate of LV pressure rise $(\mathrm{LVdp} / \mathrm{dt})$. An electromagnetic flowmeter (Statham model 4001), placed around the root of aorta, sensed aortic flow velocity. This signal was integrated to give $\mathrm{LV}$ stroke volume. The zero flow was taken as the diastole. Changes in LV contractility was assessed by either LVdp/dt or aortic flow velocity and expressed as percentage change from control which was taken as 100 percent. Mean systemic arterial pressure, LVdp/dt, aortic flow velocity, LV stroke volume and electrocardiogram were recorded simultaneously using an Electronics for Medicine model DR-8 multichannel oscilloscopic photographic recorder at a paper speed of $100 \mathrm{~mm} / \mathrm{sec}$. After the control tracing, angiotensin (valyl-5-octa peptide, Ciba) in the doses of $5 \mathrm{ng} / \mathrm{Kg} / 10 \mathrm{ml} / \mathrm{min}$ was administered intravenously. Recordings were made repeatedly during a 3 hours period of the infusion, which was subsequently followed by $50,100,50 \mathrm{ng} / \mathrm{Kg} / 10 \mathrm{ml} / \mathrm{min}$ of angiotensin.

Dog with intact circulation-Group 2 ( 7 dogs): Modification by angiotensin of the cardiac effects of epinephrine, isoproterenol and glucagon was studied. Anes- 
thesia, vagotomy and measurement of systemic arterial pressure were made by similar techniques as described in the previous group. The left ventricular pressure was obtained by a catheter inserted into the ventricle through the right common carotid artery, and LVdp/dt was measured by a similar method. Heart rate was measured with an Electronics for Medicine model cardiotachograph. Mean systemic arterial pressure (MSAP), LVdp/dt and heart rate were simultaneously recorded using the recorder at a paper speed of $1 \mathrm{~mm} / \mathrm{sec}$. After the control tracing, epinephrine $(0.01,0.1$, or $1.0 \mu \mathrm{g} / \mathrm{Kg})$, isoproterenol $(0.01,0.03$, or $0.05 \mu \mathrm{g} / \mathrm{Kg}$ ) or glucagon $(1,4$, or $16 \mu \mathrm{g} / \mathrm{Kg})$ was administered intravenously, and the changes in $\mathrm{LVdp} / \mathrm{dt}$, heart rates or MSAP to each dose were measured. These doses of 3 different drugs were chosen in order to provide a similar concentration-dependent change in LVdp/dt and HR. Repeated injections of each subsequent dose or drug were only made when all data had returned to control. After these measurements, all data were allowed to return to control, when the infusion of angiotensin ( $5 \mu \mathrm{g} /$ $\mathrm{Kg} / 10 \mathrm{ml} / \mathrm{min}$ ) was carried out. During angtiotensin infusion, similar injection of 3 drugs with 3 different doses were repeated. Group 3 (3 dogs): Effects of propranolol on the effect of angiotensin plus glucagon were evaluated. The response to glucagon during angiotensin infusion obtained in the previous group was compared with that obtained in dogs which were pretreated by propranolol $(0.5$ $\mathrm{mg} / \mathrm{Kg}$ ).

Dog papillary muscle preparation-Group 4 (3 dogs): Effects of glucagon singly or used in combination with angiotensin on the development tension of papillary muscles were evaluated in 6 papillary muscles. Dogs were anesthetized with pentobarbital sodium (30 mg/Kg i.v.). Either right or left ventricular papillary muscles were removed rapidly and suspended in a $30 \mathrm{ml}$ organ bath by a silver wire. One end attached to a muscle holder and stimulator, and the other to a force displacement transducer (Grass model FT $10 \mathrm{C}$ ) model. The papillary muscles were placed under a resting tension of $2 \mathrm{Gm}$ and stimulated through the electrode with a Grass model S4 stimulator at a rate of $30 / \mathrm{min}$, with square wave stimuli of $10 \mathrm{msec}$ duration at a voltage of $25 \%$ above threshold. Recordings were made on a Grass model 7 recorder at a paper speed of $1 \mathrm{~mm} / \mathrm{sec}$. The organ bath used in the present study was of following composition expressed as $\mathrm{Gm} / \mathrm{L} ; \mathrm{CaCl}_{2} \cdot 2 \mathrm{H}_{2} \mathrm{O}, 0.24 ; \mathrm{KCl}$ 0.42 ; dextrose 2.0 and $\mathrm{NaHCO}_{3}, 0.5$ which was equilibrated with $95 \% \mathrm{O}_{2}-5 \% \mathrm{CO}_{2}$ and had a $\mathrm{pH}$ of 7.4. The changes in the development tension by adding glucagon $(0.05,0.2$, and $0.8 \mu \mathrm{g} / \mathrm{ml})$ into the solution were compared with those of angiotensin $(1 \mathrm{ng} / \mathrm{Kg}$ ) alone and those of glucagon and angiotensin in combination.

\section{Results}

Hemodynamic effects of low concentration of angiotensin-(Group 1 dogs): Intravenous infusion of angiotensin at a rate of $5 \mathrm{ng} / \mathrm{Kg} / 10 \mathrm{ml} / \mathrm{min}$ during a period of 3 hours did not produce any changes in the left ventricular contractility as assessed by $\mathrm{LV} \mathrm{dp/dt}$ or maximum aortic velocity, $\mathrm{LV}$ stroke volume, heart rate or mean systemic arterial pressure. When more concentrated doses $(50,100,500 \mathrm{ng} / \mathrm{Kg} / 10 \mathrm{ml} / \mathrm{min})$ were used for the infusion, a dose dependent increases in systemic arterial pressure were obtained $(13 \mathrm{mmHg} \pm$ 
2.7 SE, $27 \mathrm{mmHg} \pm 5.8 \mathrm{SE}$, and $41 \mathrm{mmHg} \pm 6.6 \mathrm{SE}$ ). This BP increases manifested within several minutes, the peak responses attained and stabilized in $30 \mathrm{~min}$. At this time, the heart rate increased ( 11 beats $/ \min \pm 3.2,18$ beats $\min \pm 5.1$ and 9 beats/min \pm 3.6 ), while both $L V$ dp/dt and $L V$ stroke volume were unaffected. This BP elevation, therefore, appears to be due to an increase in peripheral vascular resistance, in which the changes in cardiac output may have a minor contribution,

Modification by angiotensin of inotropic and chronotropic effects of epinephrine, isoproterenol and glucagon-(Group 2 dogs): Each dose of epinephrine, isoproterenol and glucagon was chosen to provide a similar increase in $\mathrm{LV} \mathrm{dp/dt} \mathrm{and} \mathrm{the}$ heart rate. The increases in LV dp/dt and heart rate manifested within $5 \mathrm{sec}$ after the injection and returned to control levels in $5 \mathrm{~min}$. On the contrary, the response to glucagon lasted approximately $60 \mathrm{~min}$ following injection. Therefore, glucagon administration was made in cumulative doses. Each dose of glucagon was given when the peak inotropic and chronotropic effects to the previous dose had been attained. The interval between each injection was approximately $10 \mathrm{~min}$. The increases in heart rate and $\mathrm{LV} \mathrm{dp} / \mathrm{dt}$ produced by epinephrine, isoproterenol and glucagon, administered singly or in combination with low concentration of angiotensin $(5 \mathrm{ng} / \mathrm{Kg} / 10 \mathrm{ml} / \mathrm{min}$ ) were compared and shown in Table I. There were no significant differences between the positive inotropic effects of epinephrine or isoproterenol, used singly

Table I. Effects of Epinephrine, Isoproterenol and Glucagon on LV $\mathrm{dp} / \mathrm{dt}$ and Heart Rate Before and During Infusion of Small Angiotensin Doses $(5 \mathrm{ng} / \mathrm{Kg} / 10 \mathrm{ml} / \mathrm{min})$

\begin{tabular}{|c|c|c|c|c|c|c|}
\hline \multirow{2}{*}{ Dose $(\mu \mathrm{g} / \mathbf{K g})$} & \multicolumn{3}{|c|}{$\begin{array}{c}\text { Mean increase in } L V \mathrm{dp} / \mathrm{dt} \\
(\%)\end{array}$} & \multicolumn{3}{|c|}{$\begin{array}{l}\text { Mean increase in heart rate } \\
\text { (beats/min) }\end{array}$} \\
\hline & Before & During & $P$ value & Before & During & $P$ value \\
\hline \multicolumn{7}{|l|}{ Epinephrine } \\
\hline .01 & $14 \pm 3.1$ & $13 \pm 2.7$ & $>.1$ & $13 \pm 2.1$ & $15 \pm 4.1$ & $>.1$ \\
\hline .1 & $40 \pm 5.1$ & $38 \pm 3.3$ & $>.1$ & $53 \pm 4.6$ & $48 \pm 5.6$ & $>.1$ \\
\hline 1.0 & $50 \pm 8.4$ & $60 \pm 9.8$ & $>.1$ & $78 \pm 6.3$ & $70 \pm 7.1$ & $>.1$ \\
\hline \multicolumn{7}{|l|}{ Isoproterenol } \\
\hline .01 & $18 \pm 3.1$ & $16 \pm 4.2$ & $>.1$ & $17 \pm 3.2$ & $19 \pm 4.3$ & $>.1$ \\
\hline .03 & $43 \pm 7.2$ & $39 \pm 5.6$ & $>.1$ & $58 \pm 5.1$ & $60 \pm 6.8$ & $>.1$ \\
\hline .05 & $55 \pm 8.3$ & $57 \pm 9.3$ & $>.1$ & $80 \pm 7.2$ & $79 \pm 9.3$ & $>.1$ \\
\hline \multicolumn{7}{|l|}{ Glucagon } \\
\hline 1.0 & $16 \pm 3.2$ & $27 \pm 4.1$ & $<.05$ & $15 \pm 2.1$ & $17 \pm 4.3$ & $>.1$ \\
\hline 4.0 & $41 \pm 6.4$ & $59 \pm 5.8$ & $<.05$ & $50 \pm 4.1$ & $48 \pm 7.6$ & $>.1$ \\
\hline 16.0 & $51 \pm 7.3$ & $81 \pm 9.8$ & $<.05$ & $70 \pm 6.5$ & $81 \pm 9.8$ & $>.1$ \\
\hline
\end{tabular}

The values are the means \pm SE obtained from a group of 7 dogs. 
or during infusion of angiotensin. However, the increase in $\mathrm{LV} \mathrm{dp} / \mathrm{dt}$ which was produced by glucagon during angiotensin infusion was much greater than that obtained by glucagon alone. This difference was statistically signifcant $(\mathrm{P}<.05)$. The differences between the positive chronotropic actions of each 3 drugs, used singly and during angiotensin infusion, were insignificant. The mean blood pressure responses to the doses of each drug used singly were transient, were seen within $20 \mathrm{sec}$ after injection, and consisted of average decrease of $3 \mathrm{mmHg} \pm 0.8 \mathrm{SE}$ (epinephrine), $11 \mathrm{mmHg} \pm 2.3 \mathrm{SE}$ (isoproterenol) and $6 \mathrm{mmHg} \pm 1.7 \mathrm{SE}$ (glucagon). When these drugs were administered during infusion of low concentration of angiotensin, the mean BP changes by epinephrine or isoproterenol were similar to those obtained by single injection. Glucagon, during infusion of angiotensin, however, produced an increase in mean $\mathrm{BP}$ by an average of $8 \mathrm{mmHg} \pm 2.1 \mathrm{SE}$. Since this BP elevation was dose dependent and occurred with simultaneous potentiation of the left ventricular contractility ( $\mathrm{LV} \mathrm{dp} / \mathrm{dt}$ ), the increase in BP may be due to an increase in cardiac output, although the latter was not measured in this study.

Effect of propranolol on response to glucagon in combination with low concentration of angiotensin-(Group $3 \mathrm{dogs}$ ): The ability of glucagon, used alone, to produce positive inotropic and chronotropic effects was demonstrated in 4 dogs with propranolol $(0.5 \mathrm{mg} / \mathrm{Kg})$ pretreatment. The potentiation of the positive inotropic effect of glucagon by low concetration of angiotensin $(5 \mathrm{ng} / \mathrm{Kg} / 10 \mathrm{ml} /$ $\mathrm{min}$ ) could also be reproduced. This potentiation was similar to that obtained in dogs without propranolol (Group 2 dogs) as described above. The increases in heart rate which were produced by glucagon alone were 7 beats/ $\min \pm 1.1 \mathrm{SE}, 31$ beats $/ \min \pm 2.6 \mathrm{SE}$, and 66 beats $/ \min \pm 5.8 \mathrm{SE}$ in dogs with propranolol, which were slightly lower than those observed in dogs without propranolol (Group $2 \mathrm{dogs}$ ). The modification of the chronotropic effect of glucagon by angiotensin could likewise not be demonstrated.

Responses to glucagon, singly or in combination with angiotensin in papillary muscle preparation-(Group $4 \mathrm{dogs}$ ): Six papillary muscles of 3 dogs were exposed to 3 different doses of glucagon $(0.05,0.2$, and $0.8 \mu \mathrm{g} / \mathrm{ml})$. These glucagon concentrations were chosen to provide a similar positive inotropic response as obtained in Group 2 dogs. The isometric tension increased progressively as the concentration of glucagon was increased. This inotropic effect was sustained but it could be reversed by washing the muscle with a glucagon free medium. Repeated exposure to glucagon resulted in a similar increase in the isometric tension. The exposure of this muscle to the solution which contained angiotensin at the concentration of $0.1 \mathrm{ng} / \mathrm{ml}$ did not provide any effect on the isometric tension. The addition of glucagon of similar doses in this solution, however, resulted in a greater augmentation of isometric ten- 


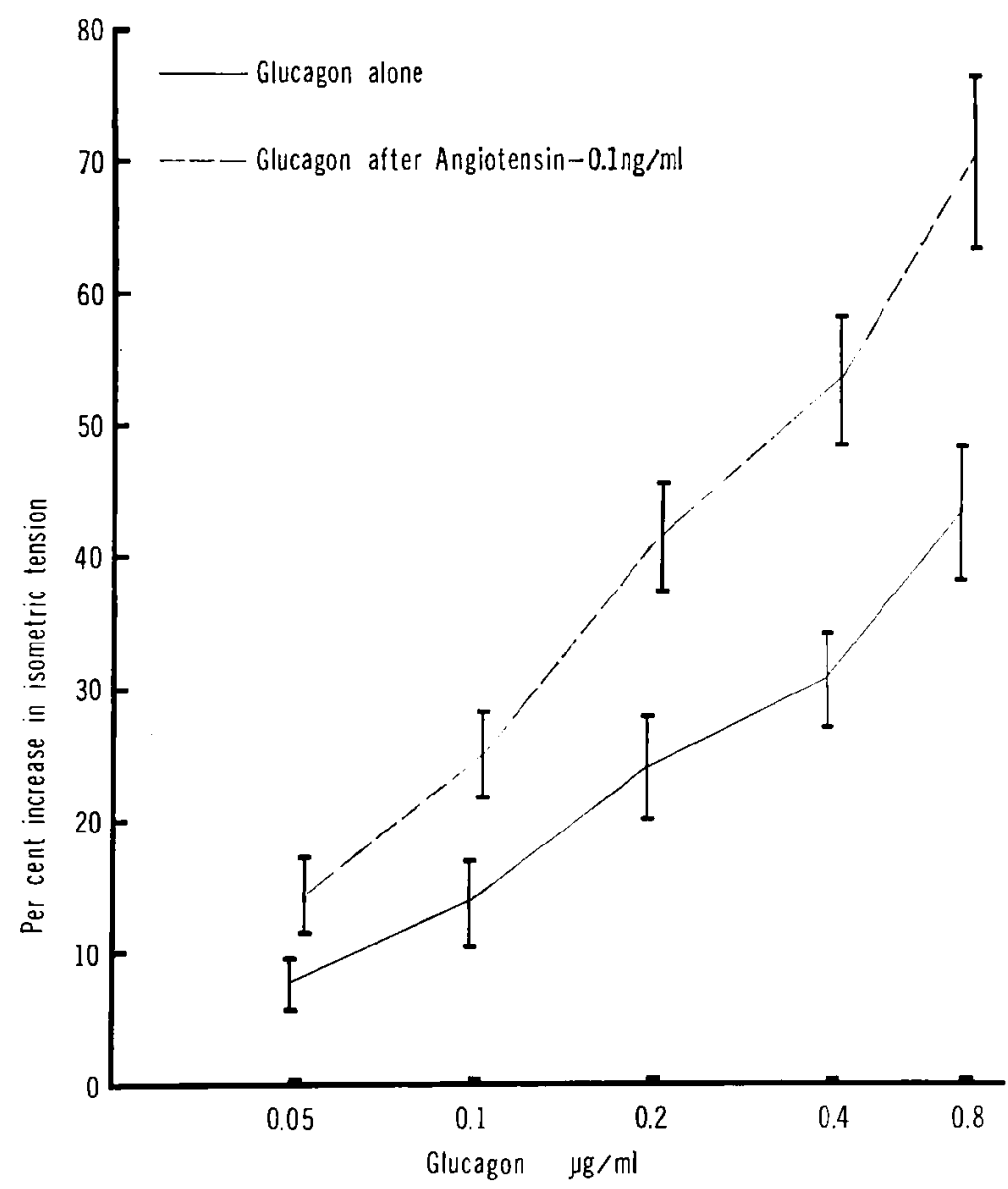

Fig. 1. Effect of an increase in the concentration of glucagon upon the development of isometric tension in the isolated dog papillary muscle. Solid line=glucagon, Dotted line=glucagon after angiotensin $(0.1 \mathrm{ng} / \mathrm{ml})$ was in the bathing solution, vertical line $=\mathrm{SE}$.

sion when compared with those occurring with glucagon alone. This difference was statistically significant $(P<0.001)$. These responses to glucagon alone and to glucagon in combination with angiotensin were compared and illustrated in Fig. 1. The recording shown in Fig. 2 is the one of the typical tracings and demonstrates the action of angiotensin for the enhancement of the inotropic effect of glucagon. These effects could be reproduced and the removal of angiotensin from the solution provided a similar responses to the subsequent addition of glucagon as those observed in these muscles during the initial exposure to glucagon. 


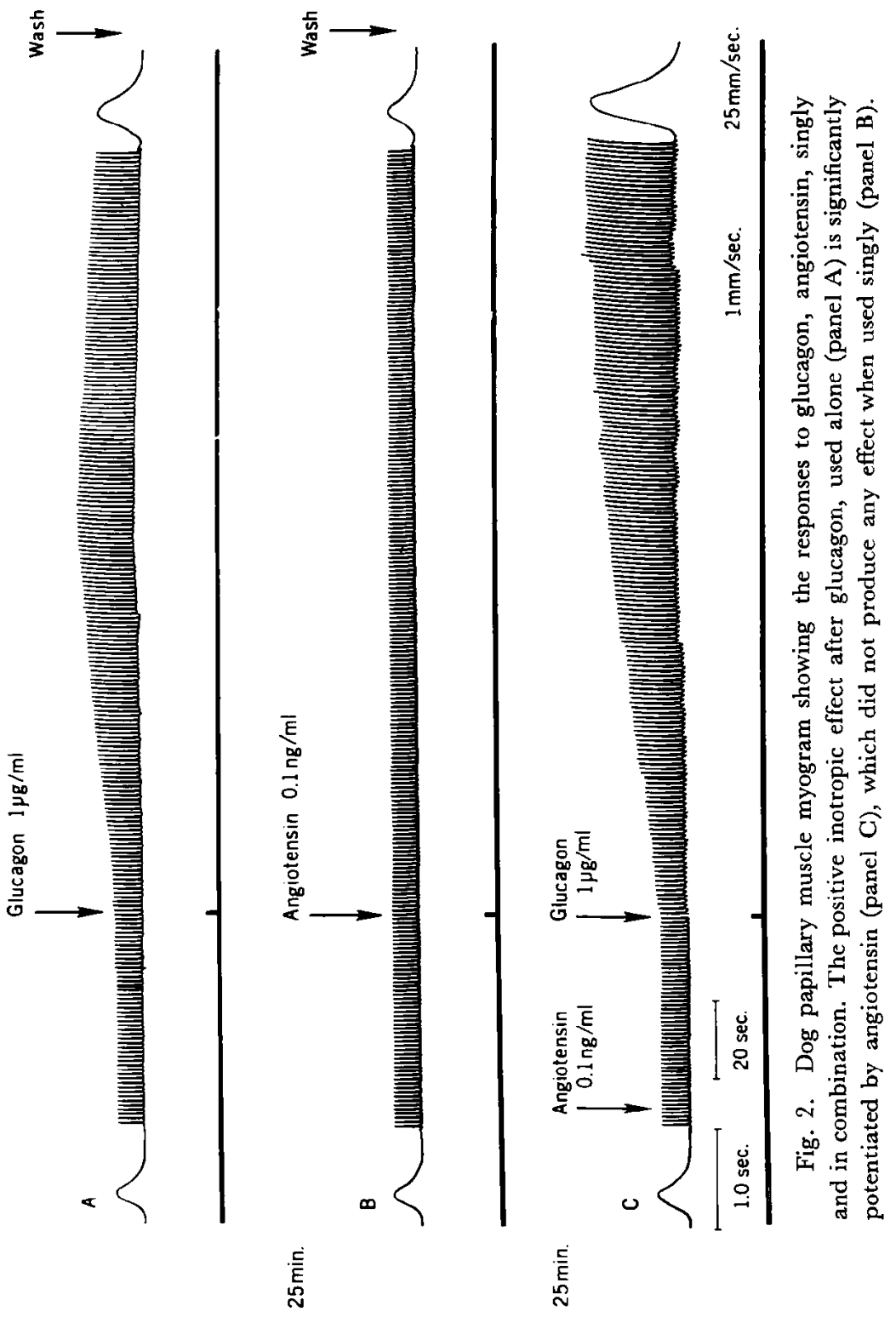

Discussion

Angiotensin, in doses which produce a pressor effect when given intravenously, has been known to produce a positive inotropic effect on the heart. This effect was demonstrated in the papillary muscles of experimental animals. ${ }^{9-13)}$ In the intact circulation, however, this effect could be greatly modified by the baroreceptor responses occurring simultaneously with the 
elevation of systemic arterial pressure. ${ }^{12}$ (13),25)-28) The pressor effects produced by intravenous administration of angiotensin are not accompanied by an increase either in myocardial contractility or cardiac output for this reason. Therefore, the increase in vascular resistance appears to be a primary factor responsible for the elevation of systemic arterial pressure. Since the action of angiotensin on myocardial contraction has been only significant at high concentrations which produce pressor effect, it is obscure whether the positive inotropic action of this agent has any contribution to the overall circulatory response to this agent. Recently, however, Koch-weser ${ }^{\mathbf{1 0}}$ ) has reported that an augmentation of the development tension of cat papillary muscles could be produced by much less concentrated angiotensin doses $\left(10^{-8}\right.$ and $10^{-9} \mathrm{M}$ ). These angiotensin concentrations appear to be insufficient to raise systemic arterial pressure when such concentration is achieved by intravenous administration. In the present study, similar low angiotensin doses were given intravenously in dogs with intact circulation. Three hours of infusion, however, produced no measurable changes in $\mathrm{LV} \mathrm{dp} / \mathrm{dt}, \mathrm{LV}$ stroke volume or systemic arterial pressure. Dickinson and Lawrence ${ }^{29}$ ) in rabbits and McCubbin et $\mathbf{a l}^{30}$ ) in unanesthetized dogs have experimentally produced a sustained hypertension by several days' continuous intravenous infusion of low angiotensin doses, which was insufficient at the beginning to raise arterial blood pressure. They noted that this hypertension was not accompanied by any increases in cardiac output. From these data, it seems unlikely that there is any direct action of angiotensin on the myocardial contractility to account for an increase in cardiac output and participate in the elevation of systemic arterial pressure.

It has been demonstrated that small doses of angiotensin are capable of facilitating the action of sympathomimetics at various organ levels, ${ }^{21,-24}$ ) although such angiotensin doses alone do not produce any hemodynamic changes. Several workers have reported that subpressor amounts of angiotensin enhance the vasoconstrictor effect of endogenous norepinephrine, $\left.{ }^{6},{ }^{2}, 1,18\right)-20$ ) and have postulated that such action of low angiotensin doses on the peripheral alpha adrenergic vasoconstrictor mechanism may be of importance regarding the pathogenesis of essential hypertension. There is controversy regarding similar action of angiotensin in enhancing the stimulant effect of inotropic agents on the heart. Beulnes et al ${ }^{21}$ ) have observed the enhancement by small doses of angiotensin on cardiac action of norepinephrine, metaraminol and tyramine. Koch-weser, ${ }^{10}$ ) however, has described that angiotensin does not release catecholamines from cardiac stores and does not stimulate adrenergic beta receptors. Peach et $\mathrm{al}^{22}$ ) have shown that very small doses of angiotensin inhibit norepinephrine uptake in the heart and produce an ino- 
tropic effect. Smyth ${ }^{23}$ ) has failed to demonstrate the enhancement by angiotensin of positive inotropic effect of epinephrine on the heart. In the present study, angiotensin did not show any significant potentiation of inotropic effect of either epinephrine or isoproterenol. However, it significantly augmented the action of glucagon on $\mathrm{LV} \mathrm{dp/dt}$, although such doses of angiotensin alone as used in this study did not produce any hemodynamic changes. Since this augmentation could be reproduced in dogs pretreated with propranolol, small doses of angiotensin may act on the heart in indirect fashion and this action appears to be independent of beta adrenergic receptor sites, which is in agreement with previous observation.10),11) Since glucagon and epinephrine have a similar metabolic action, ${ }^{31)}$ the differences found between these 2 agents are difficult to explain. Recent studies, however, have demonstrated that the inotropic effects of these 2 drugs are not mediated by the same putative receptor sites. ${ }^{32-34}$ ) The $\mathrm{Ca}^{++}$exchangeability on excitation-contraction coupling in cardiac muscles could involve several components of $\mathrm{Ca}^{++}$exchange, ${ }^{35), 36)}$ the one of which influenced by catecholamines may be different from those which are affected by glucagon, although both agents increase cyclic AMP concentration and are dependent on $\mathrm{Ca}^{++}$for the conversion of phosphorylase $b$ to phosphorylase $a^{31)-34}$

Using papillary muscle preparations, the augmentation of the inotropic effect of glucagon could be reproduced in the present study. The doses of angiotensin used for this study did not produce any changes on the development of tension in papillary muscles when used alone. These doses were chosen to provide similar concentrations as achieved by intravenous administration, and were very.small, probably approaching the circulating physiological level. ${ }^{37}$ ) This mechanism of action of angiotensin, if applicable to those postulated for the naitre of inotropic action of this agent, would be compatible with those made by Koch-weser. ${ }^{10}$ ) He postulated that angiotensin may raise contractility by augmenting entry of $\mathrm{Ca}^{++}$into the myocardial fiber. These small amounts of angiotensin and glucagon may interact through a common pathway at a $\mathrm{Ca}^{++}$exchangeability on excitation contraction coupling mechanism.

Zimmerman $^{8}$ and Hodge et al $^{37)}$ have postulated that physiological amounts of angiotensin may act to regulate vascular tone by facilitating biochemical stimuli in several vascular beds. From the data obtained in the present study, it is possible to speculate that angiotensin affects both vascular smooth muscles and ventricular myocardium at high concentrations, producing its pressor effect; yet it acts on both vascular beds and cardiac muscles by indirect fashion. The latter may be of importance regarding its role in the regulation of vascular tone and cardiac output. Some abnormality in this re- 
gulatory mechanism might be related to the etiology of high blood pressure occurring in association with increased cardiac output either in the chronic stage of experimental Goldblatt animals, or renovascular or labile hypertension in man.

\section{REFERENCES}

1. Peach MJ, Gline WH, Watts DT: Circulat Res 19: 571, 1966

2. Bickerton RK, Buckley JP: Proc Soc Exp Biol 106: 834, 1961

3. Scroop GC, Lowe RD: Nature 220: 1331, 1968

4. Cranston WI, Laveny H, Lowe RD, Rosendorff C: J Physiol 198: 301, 1968

5. Laverty R: J. Pharm Pharmacol 15: 63, 1963

6. McCubbin JW, Page IH: Circulat Res 12: 553, 1963

7. Benelli G, Della Bella D, Gandini A: Brit J Pharmacol Chemother 22: 211, 1964

8. Zimmerman BG: J Pharmacol Exp Therap 158: 1, 1967

9. Koch-weser J: Circulat Res 14: 191, 1964

10. Koch-weser J: Circulat Res 16: 230, 1965

11. Farr W, Grupp G: J Pharmacol Exp Therap 156: 528, 1967

12. Fowler NO, Holmes JC: Circulat Res 14: 191, 1964

13. Ross G: Cardiovasc Res 1: 255, 1967

14. Ledingham JM, Cohen RD: Lancet 9: 979, 1963

15. Olmsted F, Page IH: Circulat Res 16: 135, 1965

16. Frohlich ED, Ulrych M, Tarazi RC, Dustan HP, Page IH: Circulation 35: 289, 1967

17. Eich RH, Peters RJ, Cuddy RP, Sumulyan H, Lyons RH: Am Heart J 63: 188, 1962

18. Kaneko Y, Takeda T, Nakajima K, Ueda H: Circulat Res 14: 673, 1966

19. Zimmerman BG: Circulat Res 11: 780, 1962

20. Zimmerman BG, Gomez J: Intern J Neuropharmacol 4: 185, 1965

21. Beaulnes A, Nantel A, Panisset JC: Fed Proc 25: 288, 1966

22. Peach MJ, Bumpus FM, Khairallah PA: J Pharmacol Exp Therap 167: 291, 1969

23. Smyth HS: Queen's Med Rev 62: 17, 1961

24. Yu PN, Luria MN, Finlayson JK, Stanfield CA, Constantine H, Flately FJ: Circulation 24: 1325,1961

25. Downing SE, Sonnenblick EH: J Appl Physiol 18: 585, 1963

26. Berry WB, Austen WG, Clark WD: Ann Surg 159: 520, 1964

27. Kirasney JA: Am J Physiol 215: 1454, 1968

28. Dickinson CJ, Lawrence JR: Lancet 1: 1354, 1963

29. McCubbin JW, DeMoura RS, Page IH, Olmsted F: Science 149: 1394, 1965

30. Regan TJ, Lehan PH, Hennemen DH, Behar A, Hellems HK: J Lab Clin Med 63: 638, 1964

31. Lucchesi BR: Circulat Res 22: 777, 1968

32. Glick G, Parmley WW, Wechsler AS, Sonnenblick EH: Circulat Res 22: 789, 1968

33. Mayer SE, Namm DH, Rice L: Circulat Res 24: 225, 1970

34. Langer GA: Circulat Res 15: 393, 1964

35. Nayler WG: Circulat Res 21 (Suppl 3): 213, 1967

36. Hodge RL, Lowe RD, Vane JR: J Physiol 185: 613, 1966 